\title{
Global imbalances and financial fragility
}

\author{
Jong Kook Shin ${ }^{1} \quad$ Chetan Subramanian ${ }^{2}$
}

\begin{abstract}
The global financial crisis of 2008 has brought the role of global imbalances (net capital flows) front and center in the debate on the international economic outlook. The presence of large and sustained current account imbalances has led academics and policy makers to ponder over how big a threat they represent to the global economy. In this note we argue that it is the gross rather than the net capital flows which are a better indicator of the fragility of the global financial system.
\end{abstract}

\section{Global Imbalances}

Global current account imbalances are not a new phenomenon and have been around since the 80's. However, as pointed out by Serven and Nguyen (2010), two key features distinguish the global imbalances of the 80 's from the ones that we have witnessed in the last two decades - Firstly, the magnitude of the imbalances in the 80's was relatively modest compared to what we have witnessed more recently. Secondly, the external deficits of the United States and other advanced countries in the 80's were largely funded by advanced countries such as Japan and Germany. In contrast the recent imbalances of the advanced countries have been funded by emerging markets. This means that the most recent phase of global imbalances is characterized by the "Lucas Paradox," (Lucas, 1990) wherein capital flowed from poorer to richer countries. The pre-crisis debates largely centered on the sustainability of these current account imbalances and the threats they posed to the global economy.

The broad consensus in the pre-crisis period was that global imbalances were not sustainable. This was because they reflected macroeconomic imbalances such as exchange rate misalignment among major countries, the low savings rates and widened fiscal deficits of

\footnotetext{
${ }^{1}$ Management School Riddel Hall, 185 Stranmilis Road, Queen's University Belfast

Belfast BT9 5EE, UK, j.shin@qub.ac.uk, Tel: +44(0)28 9097 4428, Fax: +44(0)28 90974201

${ }^{2}$ Corresponding author: Department of Economics and Social Sciences, IIM, Bangalore, Bannergatta Road, India 560076. E-mail: chetan.s@iimb.ernet.in, Phone: (91)-80-26993345.
} 
current account deficit countries. The correction of these imbalances would necessitate a US current account adjustment, a reversal of capital flows and a major depreciation of the dollar. The general consensus among proponents of this view was that the magnitude of the exchange rate and trade adjustment required was significant and the global economy would be subject to a hard landing.

\section{Global Imbalances and the Crises}

In the wake of the crises, a number of authors have argued that global imbalances were perhaps the single largest contributing factor and therefore its elimination should be made a global priority. However, the link between global imbalances and crises is tenuous at best and must be treated with some degree of caution.

According to a prominent view, the "global savings glut" arising in emerging markets depressed world interest rates (Figure 1) and led to the formation of the asset price bubble that triggered the financial market crises. However critics (Gourinchas 2012) have pointed out that the real interest rate is determined by global savings and investment and not the pattern of its geographical distribution. In other words a given world real interest rate is equally consistent with large, small, or no current account imbalances.

Borio and Disyatat (2011), in an interesting paper point the net capital inflows and current account balances tell us little about global financing patterns - an issue which is at the core of understanding the global financial crisis. Current account numbers simply indicate changes in net claims on a country arising from trade in real goods and services and exclude for example all the transactions involving only trade in financial assets. It is however the trade in financial assets that make up a large chunk of cross border activity. It is their rapid expansion that is potentially more threatening to financial and economic stability. In the run up to the global financial crisis, for example, gross capital flows into and out of the US expanded roughly three times faster than net claims on the country, thereby indicating that the current account did not play a dominant role in determining financial flows into the US.

The weak link between net capital flows and the global financial crises has led a number of authors to look at gross instead of net positions and flows. There is a growing consensus 
that dangerous levels of gross assets can build up even in the absence of any net international flows and it is these flows which eventually set off the financial turmoil. Gross flows rose from about 10\% of world GDP in 1988 to over 30\% in 2007 (Figure 2). Borio and Disyatat (2011) find that, contrary to popular perception, a bulk of the expansion in gross capital flows had been driven by flows between advanced economies. The flows from, or between emerging markets have in contrast been relatively modest.

Broner, Didier, Erce, and Schmukler (2011) document both gross capital inflows (CIF) and gross capital outflows (COD) for the period 1970- 2009 for 103 countries. Their analysis finds that over the past four decades the volatility of gross capital flows (CIF and COD) have been large and increasing. Importantly, the volatility of net capital flows is much lower than volatility of gross capital flows. This reflects the increasing positive correlation between CIF and COD. Second, they find that gross capital flows are procyclical: During expansions foreign agents increase their purchase of domestic assets and domestic agents increase their purchase of foreign assets. During crises, especially severe ones, both CIF and COD decline, though CIF tends to fall more.

Gourinchas (2012) also argues along the same lines by focusing on gross capital flows or positions (instead of net). He takes the argument on gross flows a step further by advocating that one ought to focus on the liquidity of the gross assets and liabilities — not just the magnitudes. He points out that a mismatch between short term liabilities that need to be rolled over and a country's pledgeble assets could lead to "liquidity imbalances" making a country financially vulnerable. This point is illustrated in a simple model in the appendix.

\section{Summary and Policy Implications}

The last few years have demonstrated that capital flows can be highly volatile and liquidity, particularly in times of stress, can freeze up rapidly. The fact that a country has had access to funds in the past is no guarantee that it will continue to have that access in the future. This implies that careful attention should be paid to the pattern of gross flows as net flows would not reflect these vulnerabilities.

The period since the crises has seen the global economy characterized by a dual pattern 
of growth. On the one hand, the advanced economies which were worst hit by the crises have had a very sluggish recovery. This is in contrast to the emerging markets which have been quick to rebound and have exhibited robust growth rates. Monetary policy as a result has been set to be expansionary in the advanced economies. The differential patterns of growth and the record low interest rates have induced large capital inflows into emerging markets. Taylor (2012) points out that there is growing evidence to suggest that in order to prevent the resultant appreciation of their exchange rates, central banks in emerging markets tend to hold their interest rates lower than what would be appropriate for domestic stability. Such a policy makes these countries financially vulnerable and poses a risk to global stability. Borio and Disyatat (2011) suggest that such spillovers and externalities associated with monetary policy in individual countries call for some form of policy coordination.

Central banks also ought to rethink how they should respond to potential asset price bubbles arising out of capital flows. Conventional wisdom suggests that monetary policy should not target asset prices as there could be unintended consequences for inflation and growth. However this issue needs to be re-visited. The run up to the global financial crisis was characterized by low and stable inflation and robust growth - the so called "great moderation." Many central banks are therefore focussing on maintaining financial stability in addition to inflation and growth stability. However there needs to be a clearer understanding on the trade-offs that might arise between these objectives. Another area of focus for researchers and policy makers should be to develop tools to assess whether credit bubbles are developing.

Shortage of liquid assets continues to plague the global economic system. The crisis if anything has exacerbated the problem. Emerging markets in their quest for safe assets continue accumulating large amounts of international reserves thereby posing a threat to financial stability. As Gourinchas (2012) argues, the resolution of this so called global liquidity imbalances, which was at the heart of the crisis, is far more important than the consolidation of current account imbalances. In this regard, a systematic use of central bank swap lines and multilateral provision of liquidity under IMF supervision are all steps in the right direction.

It follows from the discussion above that gross capital flows rather than net flows (current 
account balances) have contributed to the fragility in the global financial system. Given that gross capital flows are critical in determining the health of the financial system, it becomes imperative to study and understand the composition of these flows. One of the root causes of financial crises is that liabilities are often funded by short term debt instruments. These transactions carry counterparty risk and are therefore a threat to global stability. Rogoff (2011) makes an interesting point that government policy actually incentivizes the appetite for debt. Tax systems in many countries favor debt over equity. Central banks have often bailed out debt far more aggressively than equity. Perhaps reducing the reliance on debt and increasing the share of liabilities funded by equity might make these capital flows less volatile and the financial system more resilient.

\section{Conclusion}

In this paper we argue that in assessing the financial health of a system one needs to focus on gross rather than net capital flows. The bulk of cross border flows over the last couple of decades has been characterized by transactions in pure financial assets. These transactions are not captured by net capital flows and current account balances. The current account therefore is a poor indicator of the financial soundness of a system. Given the importance of gross flows, we examine the challenges increased capital flows present to the financial stability of emerging market economies. We also focus on the implications and policy responses to increased cross-border flows. 


\section{References}

[1] Chang Roberto and Andrés Velasco, (2001). "A Model Of Financial Crises In Emerging Markets," The Quarterly Journal of Economics, MIT Press, Vol. 116(2), pages 489-517

[2] Broner, Fernando, Tatiana Didier, Aitor Erce, and Sergio Schmukler (2011), "Gross Capital Flows: Dynamics and Crises", CEPR Discussion Paper No. 8591

[3] Borio, Claudio and Piti Disyatat, (2011) "Global imbalances and the financial crisis: Link or no link?," BIS Working Papers 346, Bank for International Settlements

[4] Gourinchas, Pierre-Olivier "Global Imbalances and Global Liquidity" mimeo, (2012), University of Californina, Berkely

[5] Jr. Lucas, Robert E., (1990) "Why doesn't capital flow from rich to poor countries?" American Economic Review,80(2), pages. 92-96

[6] Servén. L and H Nguyen (2010), "Global Imbalances before and after the Global Crisis", World Bank Policy Research Working Paper 5354

[7] Rogoff, Kenneth, "Global Imbalances without Tears," http://www.projectsyndicate.org/ commentary/rogoff78/English March 2011. Project Syndicate

\section{Appendix}

\section{Model}

We present below a simple example to illustrate how despite having a sound net debt position a crisis could be triggered off by the presence of large gross debt. The model essentially follows Chang and Velasco (2001, CV) with minor modifications. We consider a small open economy with ex-ante identical agents. There are three time periods in the economy denoted by $t=0,1,2$. There exists a single good which is freely traded and whose price is fixed and is normalized at a dollar. The domestic agents are endowed with $e$ dollars. At $t=0$, goods can be invested in a foreign long term technology such that each dollar invested yields $R>1$ 
dollars at the end of period 2. However if the technology is liquidated in period 1, the return from this investment is $r<1$. On the other hand there is a world capital market that is liquid and deep. One dollar lent at $t=0$ yields a gross return of one dollar at either $t=1$ or $t=2$. Domestic agents can lend as much as they want but can borrow a maximum of $f>0$.

As in CV, each domestic agent discovers her type at $t=1$. Specifically, she discovers with probability $\lambda$ that she is impatient and derives utility only from period 1 consumption, $c_{1}$, or with probability $1-\lambda$, that she is patient and derives utility only from period 2 consumption $c_{2}$. Type realization is $i . i . \dot{d}$. across agents and there is no aggregate uncertainty. The ex ante expected utility of domestic agents is

$$
\lambda u\left(c_{1}\right)+(1-\lambda) u\left(c_{2}\right)
$$

where $u(c)$ is $\frac{c^{1-\sigma}-1}{1-\sigma}$. In such a setup with no aggregate uncertainty, Home agents can benefit from pooling their resources which rationalizes the existence of a bank. The bank maximizes the utility of the representative depositor conditional on the realization of her type. The problem is solved using the Revelation Principle wherein the social optimum is obtained by maximizing (1) subject to

$$
\begin{aligned}
k & \leq d_{0}+e \\
\lambda c_{1} & \leq d_{1}+r l \\
(1-\lambda) c_{2}+d_{0}+d_{1} & \leq R(k-l) \\
d_{0} & \leq f \\
d_{0}+d_{1} & \leq f \\
c_{1} & \leq c_{2} \\
c_{1}, c_{2}, k, l & \geq 0
\end{aligned}
$$

where $k$ denotes the amount invested in the long term overseas project, $d_{0}$ and $d_{1}$ are the foreign debts at $t=0,1$ respectively and $l$ denotes the liquidation amount of the long term project at $t=1$. Equation (2) restricts the long term investment to be less than the endowment plus borrowings. Equations (3) and (4) represent the feasibility constraints in periods 1 and 2. Equations (5) and (6) are the external feasibility constraints and (7) is 
the truth-telling constraint. Following $\mathbf{C V}$, at the social optimum, there is no wastage of resources leading to the following conditions:

$$
\begin{aligned}
\tilde{l} & =0 \\
\lambda \tilde{c}_{1} & =\tilde{d}_{1} \\
(1-\lambda) \tilde{c}_{2}+\tilde{d}_{0}+\tilde{d}_{1} & =R \tilde{k} \\
\tilde{k} & =\tilde{d}_{0}+e \\
\tilde{d}_{0}+\tilde{d}_{1} & =f
\end{aligned}
$$

where the tilde denotes the social optimal values of the respective variables. Equations (9) - (13), can be reduced to a single equation:

$$
(1-\lambda) \tilde{c}_{2}+R \lambda \tilde{c}_{1}=R w
$$

where $w \equiv e+f(R-1) / R$ and can be interpreted as the social wealth of Home country. The social optimal is obtained by maximizing (1) subject to (14) which yields

$$
\begin{aligned}
\lambda \tilde{c}_{1} & =\theta w \\
(1-\lambda) \tilde{c}_{2} & =(1-\theta) R w
\end{aligned}
$$

where $\theta=1 /\left[1+\frac{(1-\lambda)}{\lambda} R^{\frac{\sigma=1}{\sigma}}\right] \in(0,1)$. Denoting the gross and net foreign debt flows ${ }^{3}$ at the end of $t=0$ as $d_{0}$ and $n_{0} \equiv d_{0}-k$, respectively, it follows that

$$
\begin{aligned}
& \tilde{d}_{0}=\tilde{k}-e=(1-\theta) w+f / R-e \\
& \tilde{n}_{0}=-e
\end{aligned}
$$

\section{Bank Runs-Gross vs Net Capital Flows}

CV show how a decentralized bank deposit system can lead to bank runs. In the section we explore the link between gross and net capital flows and bank runs. Under the deposit system described by $\mathbf{C V}$, each agent surrenders her endowment in period 0 and capacity to

\footnotetext{
${ }^{3}$ In this simple setting, net (gross) capital flows amount to net (gross) debt flows.
} 
borrow from the international capital market to the bank. The bank implements the socially optimal borrowing and investment described in the previous section i.e. $\tilde{k}$ and $\tilde{d}_{0}$ in period 0 and $\tilde{d}_{1}$ in period 1 . In exchange, the agent is given the right to withdraw either $\tilde{c}_{1}$ in period 1 or $\tilde{c}_{2}$ in period 2 at her discretion. It is further assumed that the bank serves withdrawal requests sequentially. In other words, agents can withdraw $\tilde{c}_{1}$ in period 1 if the bank is still open upon their arrival. If the withdrawal request exceeds a preset liquidation threshold $\bar{l}$ (which will be discussed shortly), the bank closes and stops its operation. CV show that such a demand deposit system gives rise to multiple equilibria. Intuitively, if each agent expects all other agents including the patient ones to withdraw their deposits at $t=1$, it becomes optimal for an individual agent to withdraw her deposit in $t=1$. In other words it becomes optimal for an agent to withdraw deposits before the bank runs out of liquid assets (i.e. reaches its upper limit of liquidation, $\bar{l}$ ).

If the domestic banking sector can commit to repayment of all foreign debt $^{4}$, the maximum liquidation of long run project, $\bar{l}$ must satisfy

$$
R(\tilde{k}-\bar{l})=\tilde{d}_{0}+\tilde{d}_{1}
$$

Combined with (13), this condition implies

$$
\bar{l}=\tilde{k}-f / R
$$

Under this scenario, foreign lenders are always willing to give $\tilde{d}_{0}$ and $\tilde{d}_{1}$ to the bank because they know they will be repaid in full regardless of the bank's situation. When there is a bank run in period 1, the bank decides to go bankrupt if the withdrawal request exceeds the maximum liquidity available:

$$
z=\tilde{c}_{1}-\left(\tilde{d}_{1}+r \bar{l}\right)>0
$$

In other words, a bank run driven financial meltdown happens if a measure of bank illiquidity $z$ is a positive number. We next investigate the role of the net and gross foreign capital flows in such a financial crisis. Using (19), (12) and (18) we can rewrite (20) as:

$$
z=\frac{\theta w}{\lambda}-f\left(\frac{R-r}{R}\right)+(1-r) \tilde{d}_{0}+r \tilde{n}_{0}
$$

\footnotetext{
${ }^{4}$ More realistically, banks may not be able to commit to pay back all their foreign liabilities. However, it can be shown that our key results are unchanged in this settings.
} 
It follows from (21) that the illiquidity measure $z$ varies directly with both $\tilde{d}_{0}$ and $\tilde{n}_{0}$. In other words it is not just the net but also gross foreign capital flows that increase the possibility of a financial crisis.

Result: As long as the gross capital flow $\tilde{d}_{0}$ is high enough a financial crises could occur even with a negative net foreign capital $\tilde{n}_{0}$.

A financial crisis can occur due to liquidity mismatches and sentiments despite good fundamentals $(R>1)$. Since the long term investment yields higher return than borrowing costs, it is optimal for Home agents to use a leverage. However, as the size of leverage increases, the risk of a financial crisis also increases. More interestingly, it can occur as long as the size of the gross capital flow $\tilde{d}_{0}$ is large enough. Put simply, in such a setup a net capital flow need not be a good indicator of financial fragility. The presence of larger gross capital flows can trigger a crises even if the net capital flows are in balance. 
Figure 1

Real interest rate on Public debt: Long term (10 years) short term (3 months)

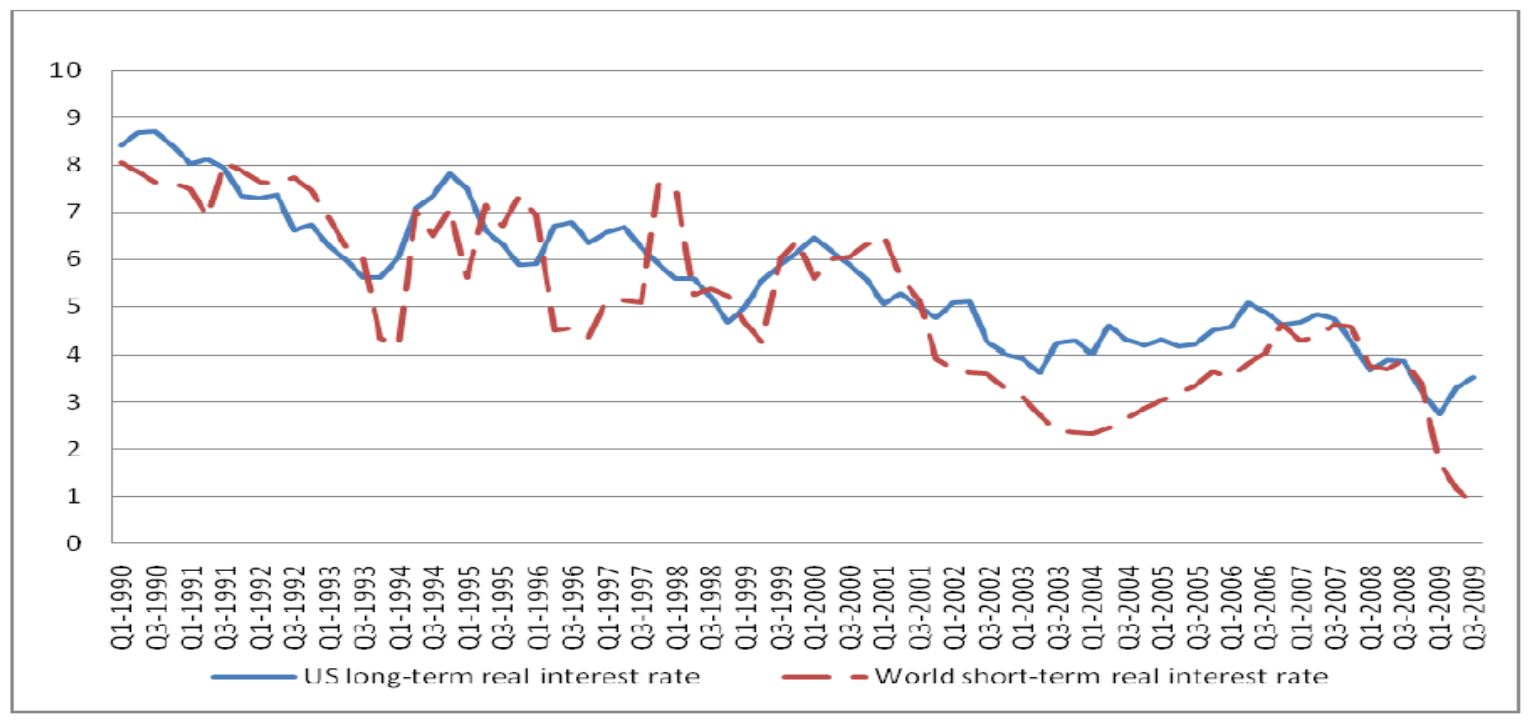

Source: Serven-Nguyen (2010) 
Figure 2

Gross capital flows as a percentage of world GDP

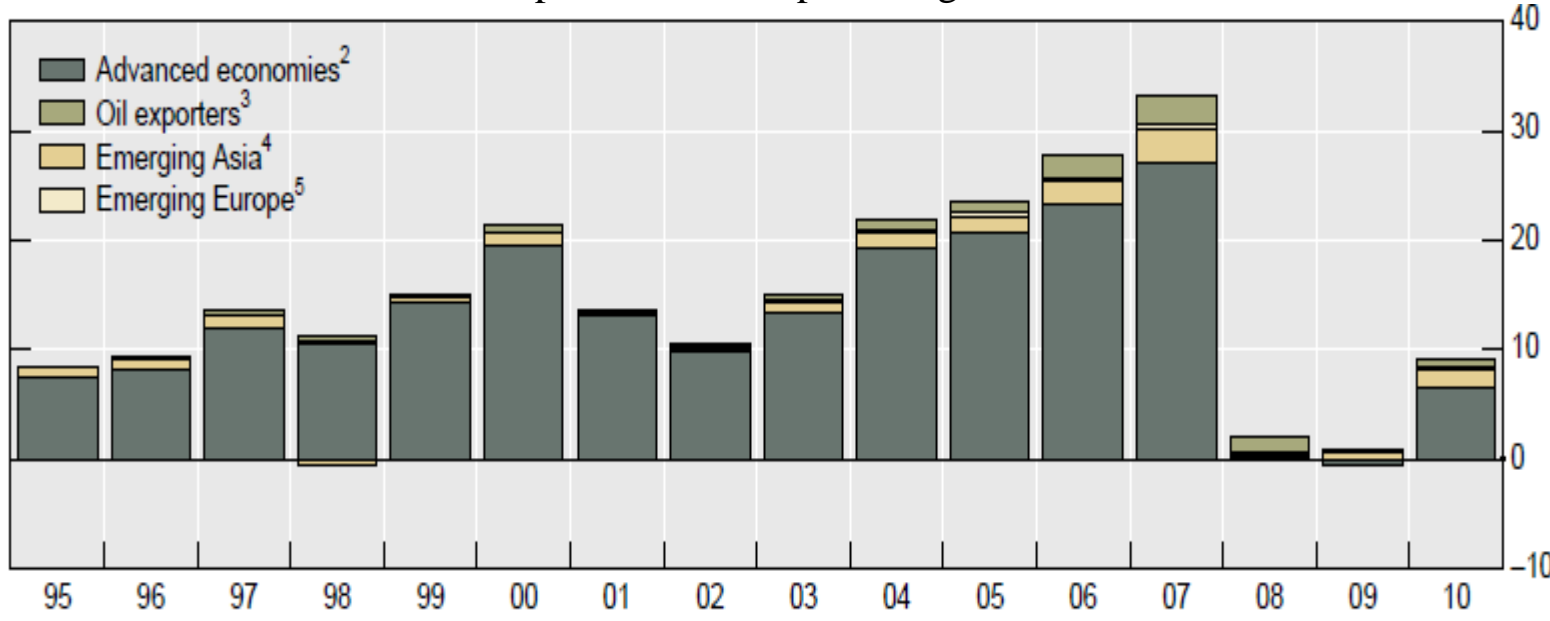

${ }^{1}$ Gross flows equals sum of inflows and outflows of direct, portfolio and other investments. ${ }^{2}$ Australia, Canada, Denmark, the euro area, Japan, New Zealand, Sweden, the United Kingdom and the United States. ${ }^{3}$ Algeria, Angola, Azerbaijan, Bahrain, Democratic Republic of Congo, Ecuador, Equatorial Guinea, Gabon, Iran, Kazakhstan, Kuwait, Libya, Nigeria, Norway, Oman, Qatar, Russia, Saudi Arabia, Sudan, Syrian Arabic Republic, Trinidad and Tobago, the United Arab Emirates, Venezuela and Yemen. ${ }^{4}$ China, Chinese Taipei, India, Indonesia, Korea, Malaysia, the Philippines, Singapore, Thailand and the 20 smaller Asian countries. ${ }^{5}$ Bulgaria, the Czech Republic, Estonia, Hungary, Latvia, Lithuania, Poland, Romania, Slovakia and Slovenia.

Source: Borio and Disyatat (2011) 